\title{
The challenge of air pollution research
}

\author{
Jonathan M. Samet • Yong S. Chung
}

Published online: 9 March 2010

(C) Springer Science+Business Media B.V. 2010

The four papers in this issue, marking the third anniversary of Air Quality, Atmosphere, and Health, illustrate the complexity of research on air pollution and the need for a multidisciplinary journal like this one. The research was carried out by authors in multiple countries (Brazil, Malaysia, and the USA), and the evidence covered is diverse, being based in atmospheric sciences, economics, epidemiology, and toxicology. The main topics covered include the atmospheric and health impacts of traffic in urban environments, the determinants of pollutant concentrations in complex urban environments, the presence and implications of ultrafine particles in urban atmospheres, and the economic evaluation of the benefits of air pollution control. All of these topics are integral to evidence-based control of air pollution.

Two of the papers are based on air pollution in cities in middle-income countries where air pollution remains a threat to public health: Sao Paulo, Brazil, and locations within the Klang Valley, Malaysia. The Sao Paulo study by Martins et al. (2010) was carried out in one of the world's largest megacities and one that is notorious for its traffic. Their measurements and modeling captured the complicated temporal variation of pollutant levels within the city and the driving influence of traffic. They also captured a component that was possibly reflective of widespread biomass burning. They emphasize the presence of ultrafines in the atmosphere

J. M. Samet $(\bowtie)$

Department of Preventive Medicine,

Keck School of Medicine and Institute for Global Health,

University of Southern California,

Los Angeles, CA 90089, USA

e-mail: jsamet@usc.edu

Y. S. Chung

Korean Center for Atmospheric Environment Research,

Choongbook 363-891, South Korea of Sao Paulo and use modeling to highlight the potential risks to health. Azmi and colleagues (2010) document air quality in the industrialized Klang Valley of Malaysia. As in Sao Paulo, heavy traffic plays a key role in driving air pollutant concentrations, and biomass burning has had a strong influence at times. Both studies should prove useful for informing local decision-making around air quality control strategies.

Grahame and Schlesinger (2010) have carried out a critical review that is relevant to interpreting the findings of the studies in Brazil and Malaysia. They consider the rapidly growing literature on traffic emissions and cardiovascular outcomes, integrating findings of epidemiologic and toxicologic research. They conclude that vehicle emissions are a major contributor to cardiovascular morbidity and mortality in the USA. This conclusion implies that the higher levels of vehicle-related pollution in lower- and middle-income countries, like Brazil and Malaysia, must also be causing adverse cardiovascular health effects. The Health Effects Institute recently published a systematic review of the evidence on exposure to traffic-related pollution and health (Health Effects Institute 2009). This review also found epidemiological and toxicologic evidence for adverse cardiovascular effects, although uncertainties were sufficient to preclude a designation of the evidence as firmly in support of causation. While Grahame and Schlesinger recommend consideration of a black carbon standard to address traffic emissions, the Health Effects Institute did not find sufficient evidence to recommend a particular indicator for monitoring. Recently, the US Environmental Protection Agency promulgated a National Ambient Air Quality Standard (NAAQS) for $\mathrm{NO}_{2}$ that calls for a new monitoring network directed at near-roadway exposures of the population (Federal Register 2010). The resulting data will provide insights into the population profile of exposure to traffic emissions. 
The fourth paper addresses the valuation of the benefits of air pollution, using a willing-to-pay approach that draws on national data sets for the USA and standard economic modeling approaches. Notably, Kim et al. (2010) find a regional variation in the valuation of benefits of air pollution reduction. The pattern of variation is sufficiently strong to lead to consideration of changes to the US Clean Air Act that would allow for a regional variation in the promulgation of NAAQS. This recommendation is inconsistent with the national nature of the Clean Air Act and the explicit exclusion of cost considerations in setting the NAAQS. Nonetheless, such empiric studies provide useful context for decision-makers.

We hope that readers from throughout the world will find these four articles to be useful. They are relevant to the many places where pollution from traffic is an increasing public health concern. We welcome your continued contributions as the journal moves into its fourth year.

\section{References}

Azmi SZ, Latif MT, Ismail AS, Liew J, Jemain AA (2010) Trend and status of air quality at three monitoring stations in the Klang Valley, Malaysia. Air Qual Atmos Health. doi:10.1007/s11869-009-0051-1

Federal Register (2010) Environmental Protection Agency; Primary National Ambient Air Quality Standards for Nitrogen Dioxide; Final Rule, 40 CFR Parts 50 and 58 (9 February 2010), pp. 6474-6537

Grahame T, Schlesinger RB (2010) Cardiovascular health and particulate vehicular emissions: a critical evaluation of the evidence. Air Qual Atmos Health. doi:10.1007/s11869-009-0047-x

Health Effects Institute (2009) Traffic-related air pollution: a critical review of the literature on emissions, exposure, and health effects. Special Report 17. Health Effects Institute, Boston

Kim SG, Cho SH, Lambert DM, Roberts RK (2010) Measuring the value of air quality: application of the spatial-hedonic model. Air Qual Atmos Health. doi:10.1007/s11869-009-0049-8

Martins LD, Martins JA, Freitas ED, Mazzoli CR, Gonçalves FLT, Ynoue RY, Hallak R, Albuquerque TTA, Andrade MF (2010) Potential health impact of ultrafine particles under clean and polluted urban atmospheric conditions: a model-based study. Air Qual Atmos Health. doi:10.1007/s11869-009-0048-9 